\section{Pacific Northwest}

National Laboratory

Operated by Battelle for the

U.S. Department of Energy

\title{
Ultrasonic Examination of Double-Shell Tank 241-AZ-102 Examination Completed August 2003
}

\author{
AF Pardini \\ GJ Posakony
}

August 2003

\footnotetext{
Prepared for the U.S. Department of Energy
} under Contract DE-AC06-76RL01830 


\title{
DISCLAIMER
}

This report was prepared as an account of work sponsored by an agency of the United States Government. Neither the United States Government nor any agency thereof, nor Battelle Memorial Institute, nor any of their employees, makes any warranty, express or implied, or assumes any legal liability or responsibility for the accuracy, completeness, or usefulness of any information, apparatus, product, or process disclosed, or represents that its use would not infringe privately owned rights. Reference herein to any specific commercial product, process, or service by trade name, trademark, manufacturer, or otherwise does not necessarily constitute or imply its endorsement, recommendation, or favoring by the United States Government or any agency thereof, or Battelle Memorial Institute. The views and opinions of authors expressed herein do not necessarily state or reflect those of the United States Government or any agency thereof.

\author{
PACIFIC NORTHWEST NATIONAL LABORATORY \\ operated by \\ BATTELLE \\ for the \\ UNITED STATES DEPARTMENT OF ENERGY \\ under Contract DE-AC06-76RL01830
}

Ty 
PNNL-14373

Rev. 0

\title{
Ultrasonic Examination of Double-Shell Tank 241-AZ-102 Examination Completed August 2003
}

\author{
AF Pardini \\ GJ Posakony
}

August 2003

Prepared for

the U.S. Department of Energy

under Contract DE-AC06-76RL01830

Pacific Northwest National Laboratory

Richland, Washington 99352 


\section{Summary}

COGEMA Engineering Corporation (COGEMA), under a contract from CH2M Hill Hanford Group (CH2M Hill), has performed an ultrasonic nondestructive examination of selected portions of DoubleShell Tank 241-AZ-102. The purpose of this examination was to provide information that could be used to evaluate the integrity of the wall of the primary tank. The requirements for the ultrasonic examination of Tank 241-AZ-102 were to detect, characterize (identify, size, and locate), and record measurements made of any wall thinning, pitting, or cracks that might be present in the wall of the primary tank. Any measurements that exceed the requirements set forth in the Engineering Task Plan (ETP), RPP-11832 (Jensen 2002) and summarized on page 1 of this document, are reported to CH2M Hill and the Pacific Northwest National Laboratory (PNNL) for further evaluation. Under the contract with CH2M Hill, all data is to be recorded on disk and paper copies of all measurements are provided to PNNL for third-party evaluation. PNNL is responsible for preparing a report that describes the results of the COGEMA ultrasonic examinations.

\section{Examination Results}

The results of the examination of Tank 241-AZ-102 have been evaluated by PNNL personnel. The ultrasonic examination consisted of two 15-in. wide scans over the entire height of the tank, one short 15in. wide scan on the top of Plate \#2, and the heat-affected zone (HAZ) of five vertical welds and one horizontal weld. Utilizing the Extended-Arm (also known as Y-Arm) scanner, the examination included the upper portion of the knuckle extending down around the knuckle approximately 12-in. and portions of the lower knuckle extending down to the lower knuckle weld area (high stress region) in 4 areas

accessible in the air slot openings. The examination was performed to detect any wall thinning, pitting, or cracking in the primary tank wall and knuckle. The knuckle was also examined using the Remotely Operated Nondestructive Examination (RONDE) system for circumferentially oriented cracking.

\section{Primary Tank Wall Vertical Scan Paths}

Two 15-in.-wide vertical scan paths were performed on Plates \#1, \#2, \#3, \#4, and \#5. A short 15-in. wide scan was also performed adjacent to the vertical scan path \#2 near the top of Plate \#2. The plates were examined for wall thinning, pitting, and cracks oriented vertically on the primary tank wall. The results indicated three areas near the top of Plate \#2 that exceeded the reportable level of $10 \%$ of the nominal thickness. There were no other areas of wall thinning in Plates \#1, \#3, \#4, or \#5 that exceeded the reportable level of $10 \%$ of the nominal thickness. No pitting or vertical crack-like indications were detected in Plates \#1, \#2, \#3, \#4, or \#5. 


\section{Primary Tank Wall Weld Scan Paths}

The HAZ of vertical welds in Plates \#1, \#2, \#3, \#4, and \#5 were examined for wall thinning, pitting, and cracks oriented either perpendicular or parallel to the weld. There were three areas in the HAZ of the vertical weld in Plate \#1 that exceeded the reportable level of $10 \%$ of the nominal thickness. There were no other areas of wall thinning in the HAZ of vertical welds in Plates \#2, \#3, \#4, and \#5 that exceeded the reportable level of $10 \%$ of the nominal thickness. No pitting or crack-like indications were detected in the weld HAZ areas in Plates \#1, \#2, \#3, \#4, and \#5.

The HAZ of the horizontal weld between Plate \#5 and the tank knuckle was examined for wall thinning, pitting and cracks oriented either perpendicular or parallel to the weld. There were no areas of wall thinning that exceeded the reportable level of $10 \%$ of the nominal thickness. No pitting or crack-like indications were detected in the weld areas on Plate \#5 side or on the knuckle side of the horizontal weld.

\section{Primary Tank Knuckle Scan Paths}

\section{Extended-Arm Scanning}

The upper portion of the knuckle area was scanned utilizing the Extended-Arm scanner attached to the AWS-5D crawler. The Extended-Arm scanned the transducers down around the knuckle approximately 12-in. from a starting position 2-in. down from the upper knuckle weld joining Plate \#5 to the knuckle. The knuckle was examined for wall thinning, pitting, and cracks oriented circumferentially around the primary tank. There were no areas that exceeded the reportable level of $10 \%$ of the nominal thickness. No pitting or circumferentially oriented crack-like indications were detected in the upper portion of the knuckle area.

Four small areas on the lower portion of the knuckle area were examined for wall thinning only utilizing the Extended-Arm scanner in areas accessible through selected air slots. The four areas examined were in air slots designated as Slot 4, Slot1, Slot A, and Slot B. There were no areas that exceeded the reportable level of $10 \%$ of the nominal thickness.

\section{Remotely Operated Nondestructive Examination Scanning}

The results of the RONDE ultrasonic examination of the knuckle region of Tank 241-AZ-102 provided by COGEMA have been evaluated by PNNL personnel. The results of the examination of Tank 241-AZ-102 indicated no circumferential crack-like indications were present anywhere in the knuckle region between the upper knuckle weld and the lower knuckle weld over the approximately 270 circumferential inches scanned. 


\section{Contents}

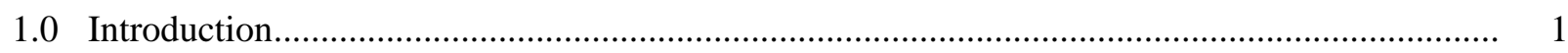

2.0 Qualified Personnel, Equipment, and Procedure ............................................................ 2

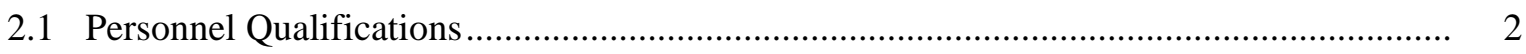

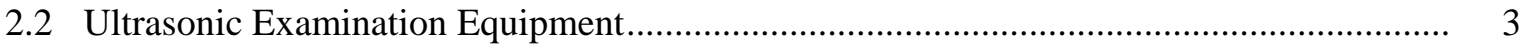

2.3 Ultrasonic Examination Procedure ……........................................................................... 3

3.0 Ultrasonic Examination Configuration .................................................................... 4

3.1 Primary Tank Wall Transducer Configuration ............................................................ 4

3.2 Weld Zone Transducer Configuration .......................................................................... 5

3.3 Knuckle Area Transducer Configuration....................................................................... 7

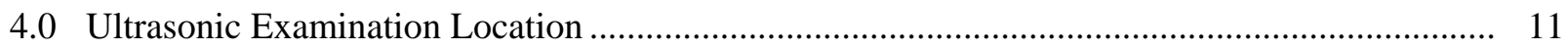

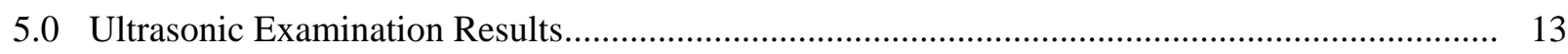

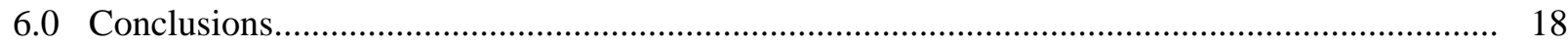

6.1 Primary Tank Wall Vertical Scan Paths ...................................................................... 18

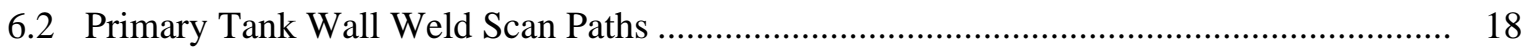

6.3 Primary Tank Knuckle Scan Paths ............................................................................ 19

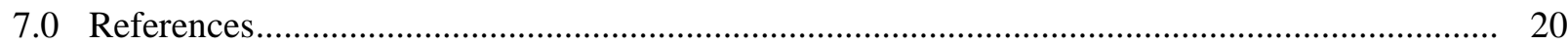




\section{Figures}

3.1 Transducer Configuration for Examining the Primary Tank Wall...................................... 4

3.2 Transducer Configurations for Examination of Weld Zone in the Primary Tank Wall........... 5

3.3 Views of the Weld Zone to be Ultrasonically Examined in the Primary Tank Wall .............. 6

3.4 Sketch of a Section of the Knuckle Examined with the Extended-Arm Scanner .................... 7

3.5 Lower Knuckle Examination in Air Slot Regions (End View) ........................................... 8

3.6 Lower Knuckle Examination in Air Slot Regions (Side View) …........................................ 8

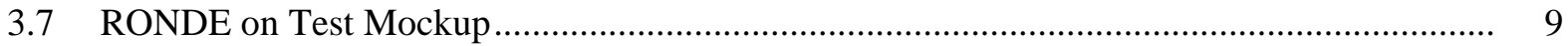

3.8 General Knuckle Scanning Arrangement.................................................................... 10

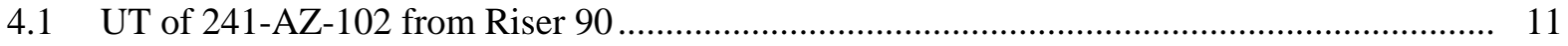

4.2 Sketch of Scan Paths on Tank 241-AZ-102 ................................................................. 12

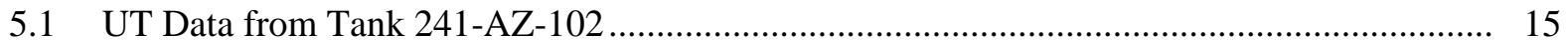

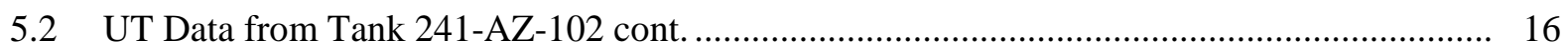

5.3 UT Data from Tank 241-AZ-102 Knuckle Region............................................................ 17 


\subsection{Introduction}

COGEMA Engineering Corporation (COGEMA), under a contract from CH2M Hill Hanford Group (CH2M Hill), has performed an ultrasonic nondestructive examination (UT) of selected portions of Double-Shell Tank (DST) 241-AZ-102. The purpose of this examination was to provide information that could be used to evaluate the integrity of the DST. The requirements for the UT of Tank 241-AZ-102 were to detect, characterize (identify, size, and locate), and record measurements made of any wall thinning, pitting, or cracks that might be present in the wall of the primary tank. Any measurements that exceed the requirements set forth in the Engineering Task Plan (ETP), RPP-11832 (Jensen 2002), are reported to CH2M Hill and the Pacific Northwest National Laboratory (PNNL) for further evaluation. Specific measurements that are reported include the following:

- Wall thinning that exceeds $10 \%$ of the nominal thickness of the plate.

- Pits with depths that exceed $25 \%$ of the nominal plate thickness.

- Stress-corrosion cracks that exceed 0.10-in. (through-wall) that are detected in the inner wall of the tank, heat-affected zone (HAZ) of welds, or in the tank knuckle and tank bottom.

The accuracy requirements for ultrasonic measurements for the different types of defects are as follows:

- Wall thinning - measure thickness within \pm 0.020 -in.

- Pits - size depths within \pm 0.050 -in.

- Cracks - size the depth of cracks on the inner wall surfaces within \pm 0.1 -in.

- Location - locate all reportable indications within \pm 1.0 -in.

Under the contract with CH2M Hill, all data is to be recorded on disk and paper copies of all measurements are provided to PNNL for third-party evaluation. PNNL is responsible for preparing a report that describes the results of the COGEMA UT. 


\subsection{Qualified Personnel, Equipment, and Procedure}

Qualification of personnel participating in the DST inspection program, the UT equipment (instrument and mechanical scanning fixture), and the UT procedure that will be used in the examination of the current DST is required by CH2M Hill. Personnel participating in the examinations are to be certified in accordance with the American Society for Nondestructive Testing (ASNT) Guideline SNTTC-1A-92 and associated documentation is to be provided. The capability of the UT system is to be validated through a performance demonstration test (PDT) administered by PNNL on a mock-up simulating the actual DST. The current procedure for the UT is to be based on the Section V, Article 4, Boiler and Pressure Vessel Code defined by the American Society for Mechanical Engineers (ASME).

\subsection{Personnel Qualifications}

The following individuals were qualified and certified to perform UT of the Hanford DST 241-AZ102:

- Mr. Wesley Nelson, ASNT Level III (\#LM-1874) in UT, has been identified as COGEMA's UT Level III authority for this project. Mr. Nelson has been certified by COGEMA as a UT Level III in accordance with COGEMA procedure COGEMA-SVCP-PRC-014, latest revision. Further documentation has been provided to establish his qualifications. Reference: Letter from PNNL to C.E. Jensen dated August 22, 2000, "Report on Performance Demonstration Test - PDT, May 2000" and "SAFT/T-SAFT Performance Demonstration Test (PDT) (Mr. Wesley Nelson)," dated November 14, 2002.

- Mr. James B. Elder, ASNT Level III (\#JM-1891) in UT, has been contracted by COGEMA to provide peer review of all DST UT data. Mr. Elder has been certified by JBNDT as a UT Level III in accordance with JBNDT written practice JBNDT-WP-1, latest revision. Further documentation has been provided to establish his qualifications. Reference: PNNL-11971, Final Report - Ultrasonic Examination of Double-Shell Tank 241-AN-107.

- Mr. William D. Purdy, COGEMA UT Level II limited (for P-Scan data acquisition only). Mr. Purdy has been certified in accordance with COGEMA procedure COGEMA-SVCP-PRC-014, latest revision. Further documentation has been provided to establish his qualifications. Reference: Letter from PNNL to C.E. Jensen dated October 5, 2001, "Purdy Performance Demonstration Test (PDT) Report.” 


\subsection{Ultrasonic Examination Equipment}

CH2M Hill has provided the UT equipment for the examination of Tank 241-AZ-102. This equipment consists of a Force Institute P-Scan ultrasonic test instrument and a Force Institute AWS-5D remote-controlled, magnetic-wheel crawler for examining the primary tank wall. Ultrasonic transducers used for the examinations are commercial off the shelf. The P-Scan ultrasonic system has been qualified through a PDT administered by PNNL. Reference: PNNL-11971, Final Report- Ultrasonic Examination of Double-Shell Tank 241-AN-107.

CH2M Hill and PNNL have provided the UT equipment for the examination of the knuckle region of Tank 241-AZ-102. This equipment consists of a Force Institute AWS-5D remote-controlled, magneticwheel crawler for transporting the PNNL RONDE scanning bridge. Ultrasonic transducers used for the examinations are commercial off the shelf. The RONDE ultrasonic system has been qualified through a PDT administered by PNNL. Reference: E-mail from Gerald J. Posakony to Susan L. Crawford and Allan F. Pardini, dated September 27, 2002, "SAFT-T-SAFT PDT.”

\subsection{Ultrasonic Examination Procedure}

COGEMA has provided the UT procedure for the examination of Tank 241-AZ-102. This procedure, COGEMA-SVUT-INS-007.3, Revision 1, outlines the type of UT and mechanical equipment that are to be used as well as the types of transducers. Both straight-beam and angle-beam transducers are used for the examination of the primary tank wall and the HAZ of selected primary tank vertical and horizontal welds. The examination procedures include full documentation on methods for calibration, examination, and reporting. Hard copies of the T-Scan (thickness) and P-Scan (projection or angle beam) views of all areas scanned are made available for analysis. The UT procedure requires the use of specific UT transducers for the different examinations. A calibration performed before and after the examinations insures that each transducer used in the inspection is adjusted and that the entire system is performing correctly. The COGEMA UT procedure has been qualified through a PDT. Reference: PNNL-11971, Final Report - Ultrasonic Examination of Double-Shell Tank 241-AN-107.

COGEMA has provided the RONDE UT procedure for the examination of Tank 241-AZ-102. This procedure, COGEMA-SVUT-INS-007.5, Revision 0, outlines the type of UT and mechanical equipment that are to be used as well as the types of transducers. Only angle-beam transducers are used for the examination of the knuckle region of the primary tank wall. The examination procedures include full documentation on methods for calibration, examination, and reporting. Hard copies of the SAFT/TSAFT views of all areas scanned are made available for analysis. The UT procedure requires the use of specific UT transducers for the knuckle examinations. A calibration performed before and after the examinations identifies the specific transducers used and the sensitivity adjustments needed to perform the inspection. The COGEMA UT procedure has been qualified through a PDT administered by PNNL. Reference: "SAFT/T-SAFT Performance Demonstration Test (PDT) (Mr. Wesley Nelson)," dated November 14, 2002. 


\subsection{Ultrasonic Examination Configuration}

COGEMA is required to inspect selected portions of the DSTs which may include the primary and secondary tank walls, the HAZ of the primary tank vertical and horizontal welds, and the tank knuckle and bottoms. The P-Scan system has been configured to perform these examinations and has been performance tested. The examination of Tank 241-AZ-102 included UT of the primary tank wall, the HAZ of selected welds in the primary tank wall, the upper portion of the knuckle extending axially downward from the upper knuckle weld approximately 12-in., selected portions of the knuckle in the air slot openings that extend to the lower knuckle weld, the entire knuckle region for circumferentially oriented stress corrosion cracks utilizing the RONDE system, and under the tank within the air slots.

\subsection{Primary Tank Wall Transducer Configuration}

Figure 3.1 provides an example of the scanning configuration generally used during an examination of the primary tank wall. However, other configurations can be used at the discretion of the COGEMA UT Level III (i.e., 45-degree transducers can be removed for simple wall thickness measurements). The functional diagram in Figure 3.1 shows one straight-beam and two angle-beam transducers ganged together for examining the primary tank wall. The straight beam is designed to detect and record wall thinning and pits, and the angle beams are designed to detect and record any cracking that may be present. These transducers are attached to the scanning bridge and they all move together. Information is captured every 0.035-in. (or as set by the NDE inspector) as the assembly is scanned across a line. At the end of each scan the fixture is indexed 0.035-in. (or as set by the NDE inspector) and the scan is repeated. The mechanical scanning fixture is designed to scan a maximum of 15-in. and then index for the next scan. The hard copy provides a permanent record that is used for the subsequent analysis.

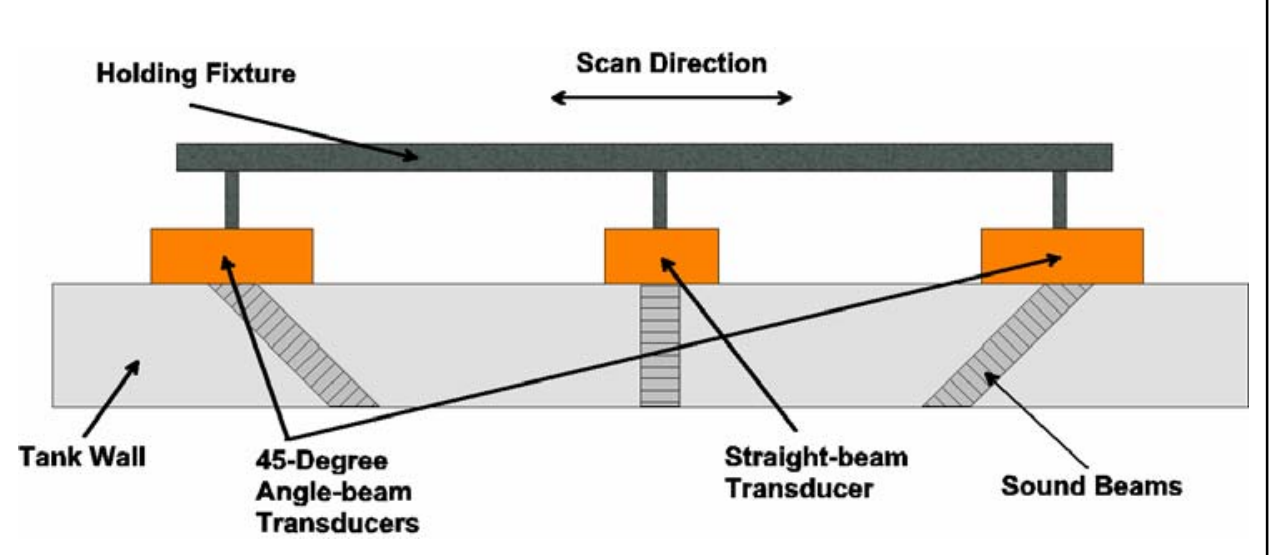

Transducer Specifications:

Angle-Beam

Type: MWB-45 04E

Frequency: $4 \mathrm{MHz}$

Size: 8 X $9 \mathrm{~mm}$

Manufacturer: Krautkramer

Straight-Beam

Type: MSEB 5B

Frequency: $5 \mathrm{MHz}$

Size: Dual - 2 X 8 mm

Manufacturer: Krautkramer

Figure 3.1. Transducer Configuration for Examining the Primary Tank Wall 


\subsection{Weld Zone Transducer Configuration}

Figure 3.2 is a functional sketch that shows the configurations for examination of the weld zone. The area of interest (HAZ of the weld) is shown as lying adjacent to the weld. Both cracks and pitting may occur in this region. The "A" portion of this sketch shows the 60-degree angle-beam transducers used for detecting cracks parallel to the weld. The straight-beam transducers in this sketch are used for detecting and recording any pitting or wall thinning that may be present. All transducers are ganged together. The scanning distance traveled is limited to a total of approximately 5.0-in. The sketch titled "B" shows the arrangement for detecting cracks that may lie perpendicular to the weld. Four 45-degree, angle-beam transducers are used for this inspection. Again the transducers are ganged together but the scan is limited to a total of approximately 4.0-in. The weld zone requirements are shown in Figure 3.3. The scan protocol, data capture, and index are the same for examining other weld areas in the tank.

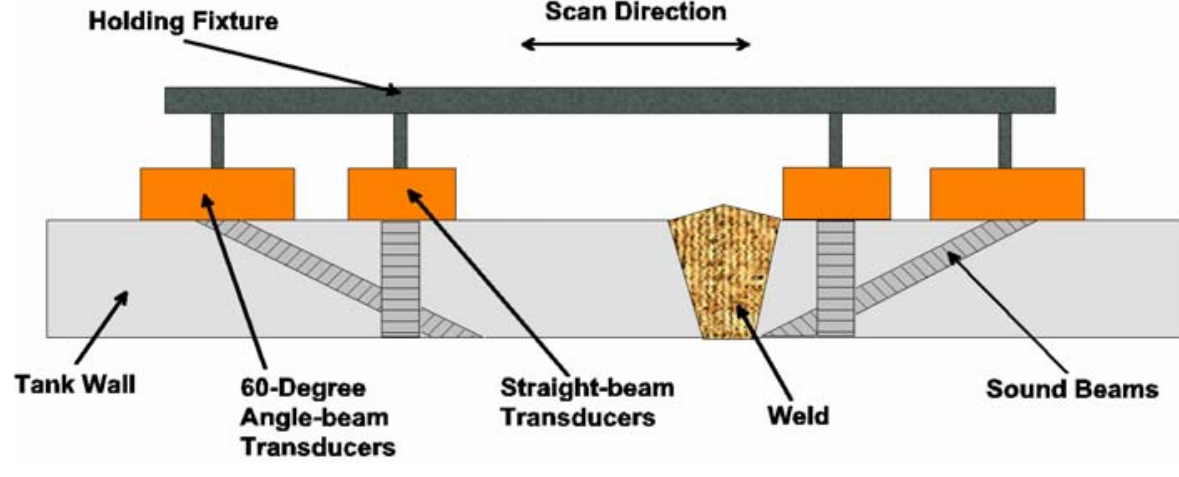

A. Configuration for pitting and cracks parallel to weld

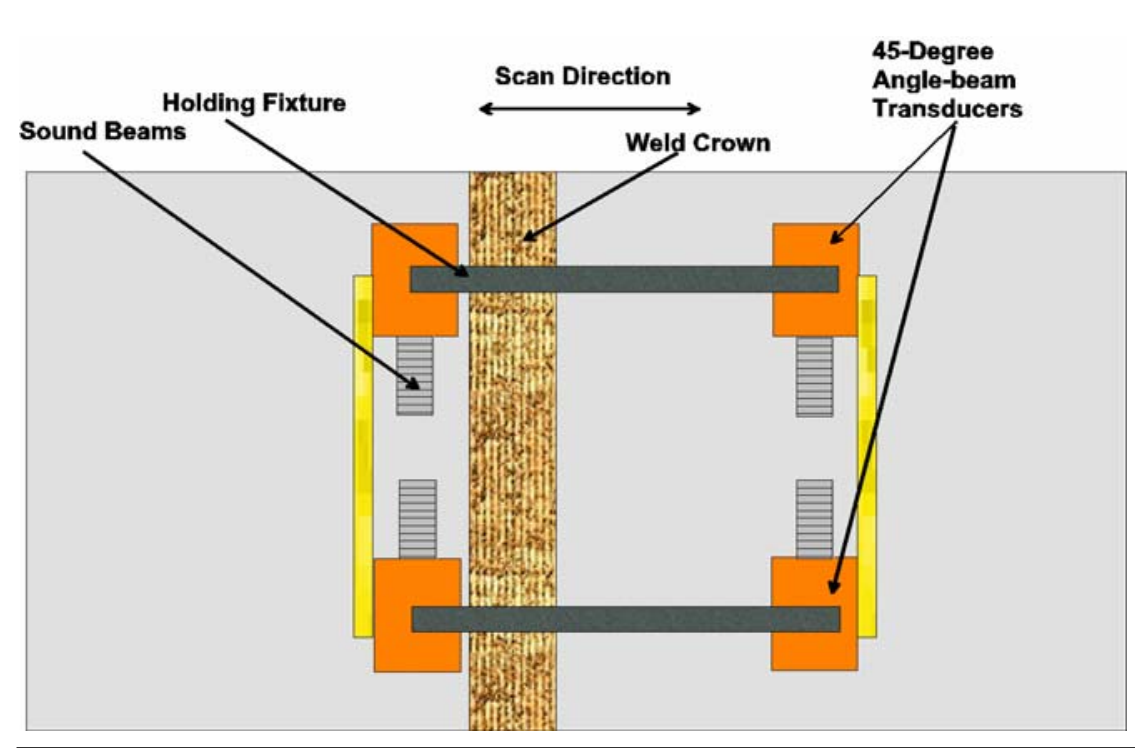

B. Configuration for cracks perpendicular to weld

\section{Transducer Specifications:}

Angle-Beam

Type: MWB-60 04E

Frequency: $4 \mathrm{MHz}$

Size: 8 X $9 \mathrm{~mm}$

Manufacturer: Krautkramer

Straight-Beam

Type: MSEB 5B

Frequency: $5 \mathrm{MHz}$

Size: Dual - 2 X 8 mm

Manufacturer: Krautkramer

\section{Transducer Specifications:}

Angle-Beam

Type: MWB-45 04E

Frequency: $4 \mathrm{MHz}$

Size: 8 X $9 \mathrm{~mm}$

Manufacturer: Krautkramer

Figure 3.2. Transducer Configurations for Examination of Weld Zone in the Primary Tank Wall 
In the HAZ, the requirement for characterizing cracks that lie perpendicular or parallel to welds in the primary tank wall is described in Figure 3.3. The HAZs are located on either side of the weld and defined as being within 1-in. of the toe of the weld and on the inner three-quarters of the thickness (3/4T) of the plate. These zones are considered most likely to experience stress-corrosion cracking.
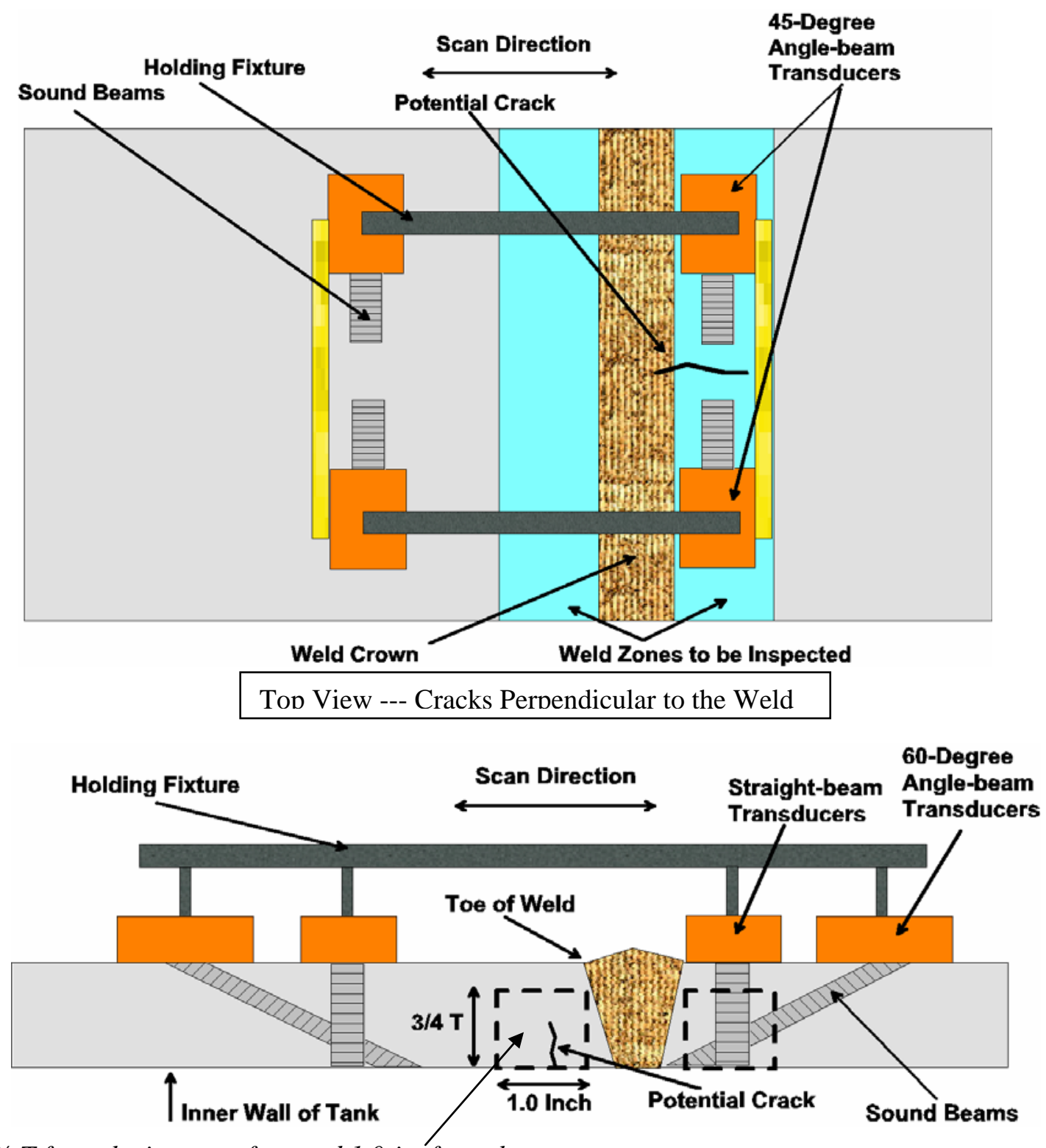

A zone $3 / 4$ T from the inner surface and 1.0-in. from the toe of the weld is to be ultrasonically examined for cracking, corrosion or pitting. Examinations are to be made on both sides of the weld.

$$
\text { End View --- Cracks Parallel to the Weld }
$$

Figure 3.3. Views of the Weld Zone to be Ultrasonically Examined in the Primary Tank Wall 


\subsection{Knuckle Area Transducer Configuration}

\subsubsection{Extended-Arm Scanning System}

Examination of the knuckle utilizes a modified scanning bridge known as the Extended-Arm scanner. The Extended-Arm provides scanning of the transducers directly on the knuckle region. The ExtendedArm is a special fixture that attaches to the AWS-5D magnetic wheel crawler. Its purpose is to extend the reach of the transducer assembly. This extension allows the transducer assembly to follow the curve of the upper portion of the knuckle below the transition Plate \#5 to upper knuckle weld. It is designed to hold the dual 0-degree or two 45-degree transducers in the same configuration as used for the examination of the tank wall. The transducer configuration used for crack detection in this examination was two opposing 45-degree angle-beam transducers that were rotated 90-degrees from the orientation used for the wall crack inspection. This configuration is designed to detect cracks that are in a circumferential direction with respect to the axis of the tank. Figure 3.4 is a sketch showing the area of the section of the knuckle examined using the Extended-Arm fixture. With the transducer positioned 2-in. below the transition Plate \#5 to upper knuckle weld, the scanning bridge was set to scan the transducer downward an additional distance of approximately 12 -in. in 0.035 -in steps (or as set by the operator). Upon completion of the scan, the bridge was indexed circumferentially 0.035 -in. (or as set by the operator) and the scan downward is repeated to obtain a pixel size 0.035 -in. x 0.035 -in. (or as set by the operator).

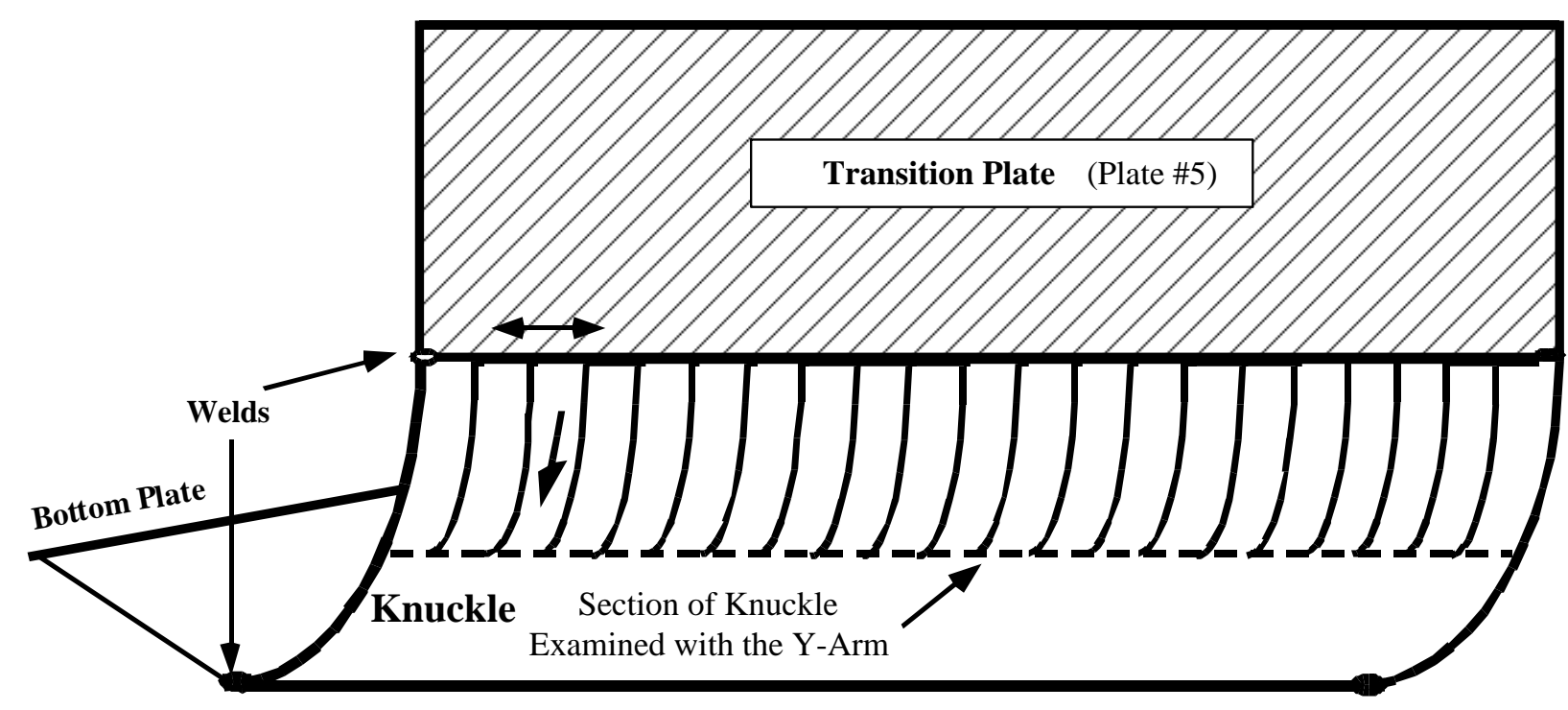

Figure 3.4. Sketch of a Section of the Knuckle Examined with the Extended-Arm Scanner 
Additional Extended-Arm scanning was done on areas that were accessible in the air slots that extend under the tank in the concrete support foundation. Figure 3.5 provides an end view (looking down the air slot) and Figure 3.6 provides a side view (looking along the circumference of the tank) of the examination of the lower knuckle in the region of the air slots.

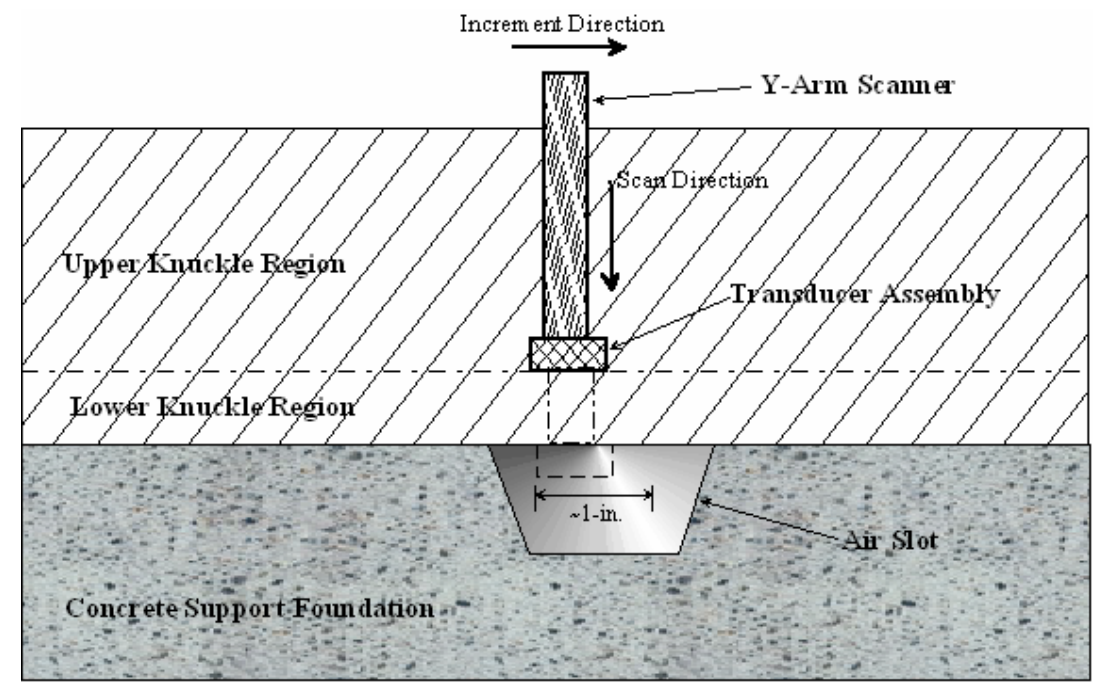

Figure 3.5. Lower Knuckle Examination in Air Slot Regions (End View)
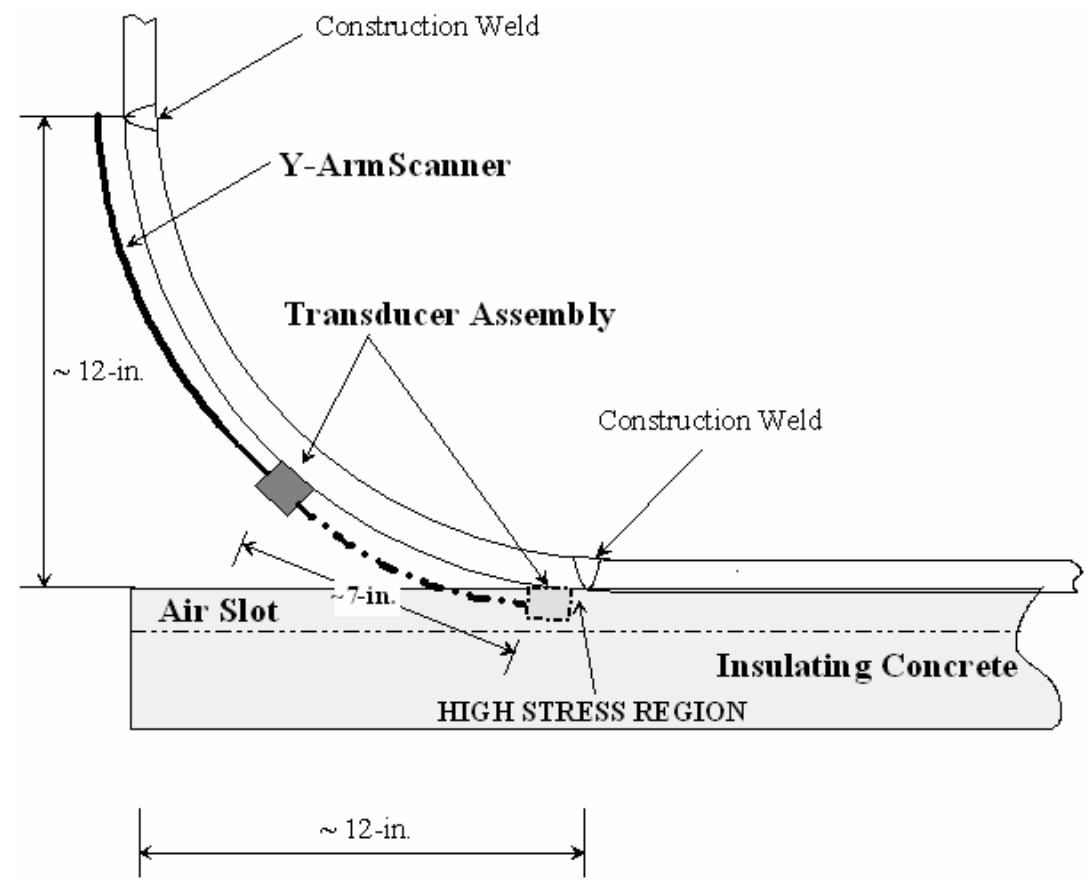

Figure 3.6. Lower Knuckle Examination in Air Slot Regions (Side View) 


\subsubsection{Remotely Operated Nondestructive Examination System (RONDE)}

The RONDE system has been configured to perform the examination of the high stress region of the primary tank knuckle. The RONDE examination of Tank 241-AZ-102 concentrated on the knuckle region from the upper knuckle weld to the lower knuckle weld (approximately 19-in. measured on the inside diameter) and extended circumferentially around the tank approximately 270-in. Figure 3.7 provides an image of the actual equipment and configuration for the examination of the knuckle region of the primary tank and the approximate location of the scanner during normal operation.

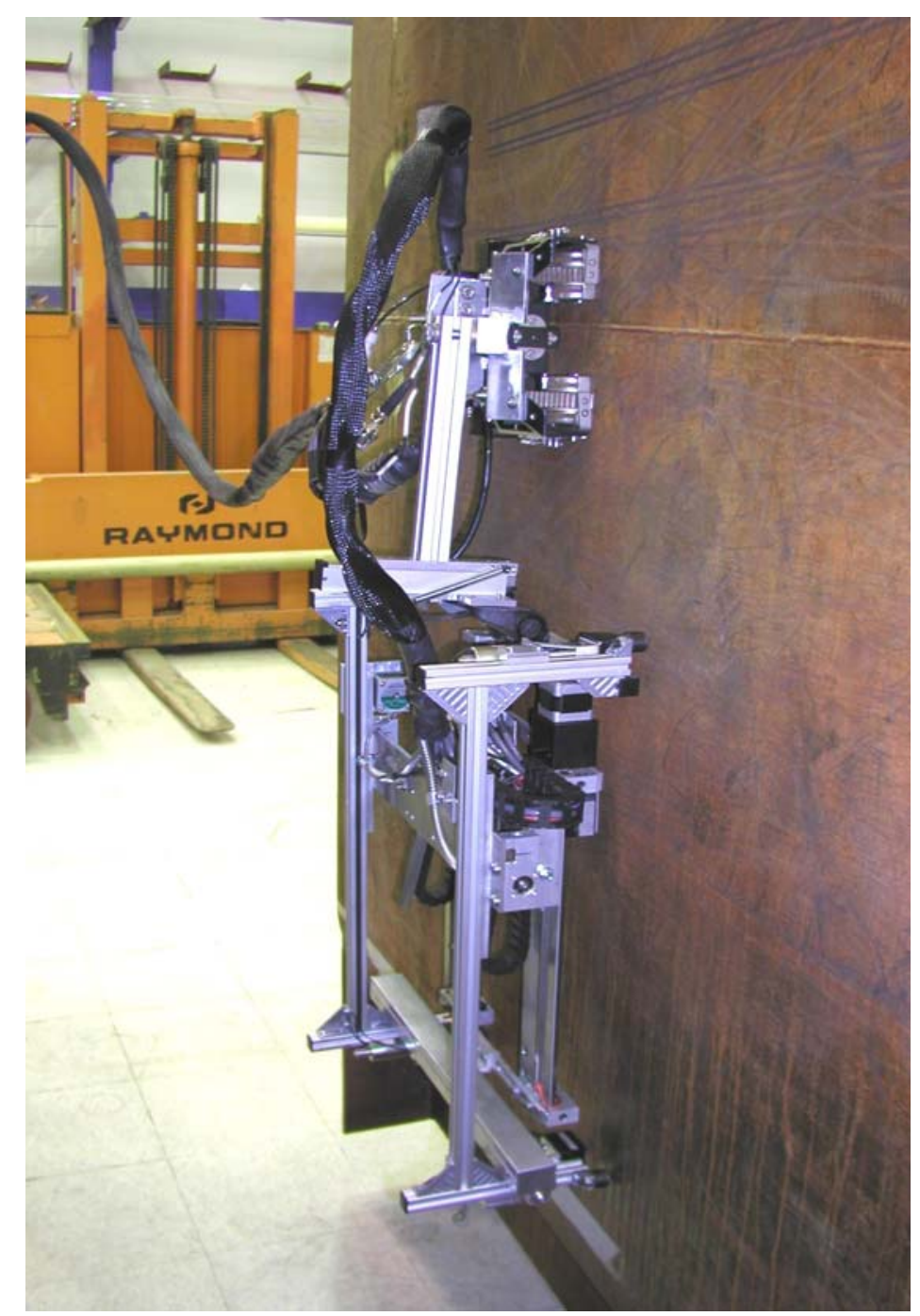

Figure 3.7 RONDE on Test Mockup

The functional diagram in Figure 3.8 shows two $70^{\circ}$ angle-beam transducers in a pitch-catch arrangement for examining the knuckle region of the primary tank. The angle beam transducers are designed to detect and record any circumferential cracking that may be present. These transducers are 
attached to the scanning bridge and can move together or individually. During crack detection scanning, the two transducers move together in unison, transducer A "pitching the sound" and transducer B "catching the sound." If a crack is detected, the two transducers are operated individually in a passing motion allowing for sizing of the detected crack. During detection scanning, information is captured every 0.025-in. (or as set by the NDE inspector) as the transducers are scanned down towards the knuckle. At the end of each scan line, the fixture is incremented 0.25-in. (or as set by the NDE inspector) and the next scan line is acquired. The mechanical scanning fixture is designed to scan the transducers approximately 10 -in. by 12.5 -in.; however, the sound field from the $70^{\circ}$ transducer interrogates the entire volume of the knuckle and the C-scan (plan view) display of the data shows the entire knuckle, from the upper knuckle weld to the lower knuckle weld, and 12.5-in. in circumference. This C-scan display is immediately evaluated to identify any crack-like indications which may require additional scanning for sizing. If no crack-like indication is identified in the 12.5-in. circumferential area scan of the knuckle, the crawler transports the bridge to the next area. The hard copy C-scan view provides a permanent record that can be used for any subsequent analysis.

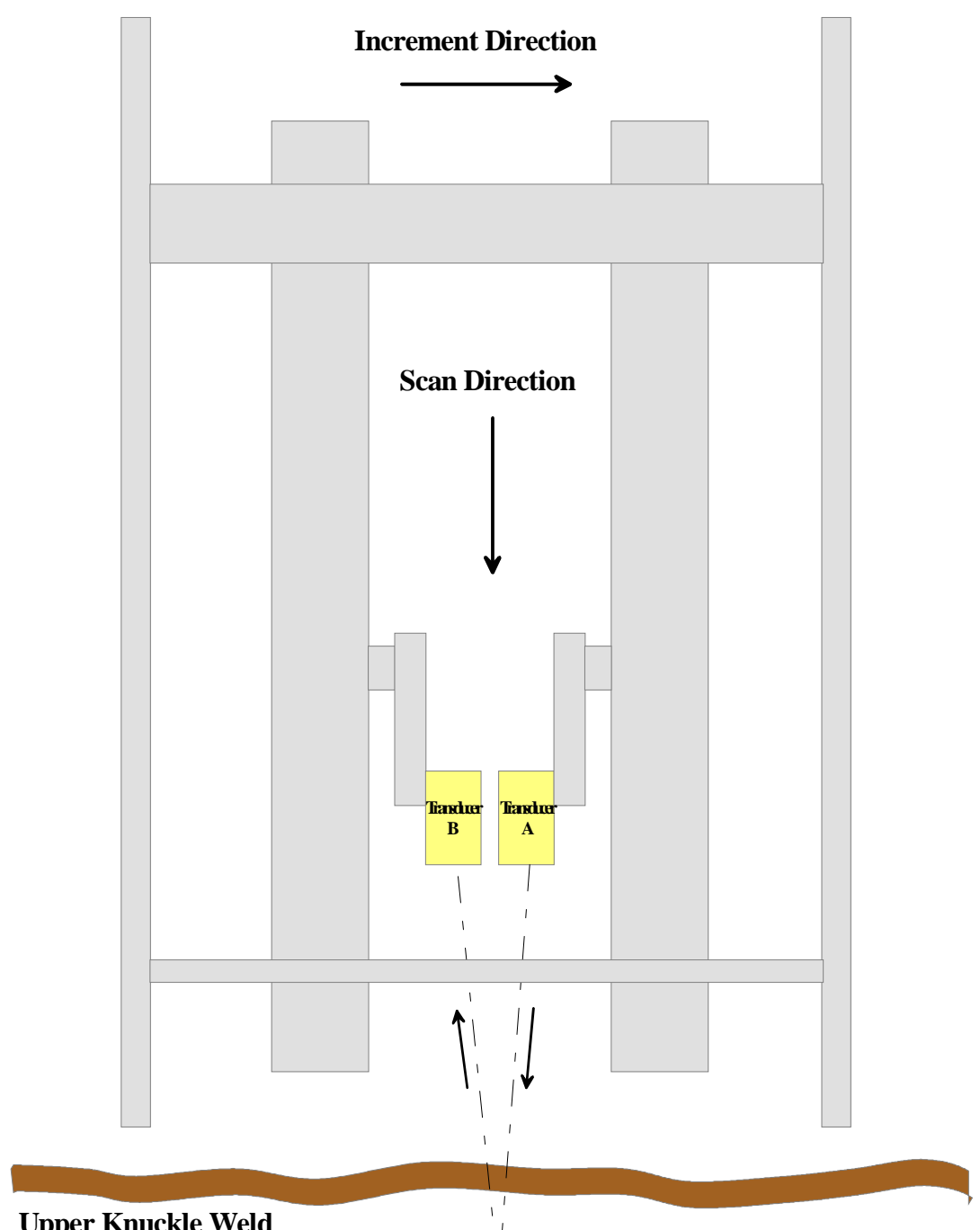

Transducer Specifications: Type: MSW-QC Benchmark Frequency: $3.5 \mathrm{MHz}$ Size: 0.5-in. Diameter Angle: 70 degree, Wedge W-213 Manufacture: Krautkramer

Figure 3.8 General Knuckle Scanning Arrangement 


\subsection{Ultrasonic Examination Location}

Tank 241-AZ-102 is located in the Hanford 200 East area in AZ Tank Farm. The crawler and associated scanner that hold the transducers were lowered into the 24-in. riser located on the north side of 241-AZ-102 and designated as Riser 90. Riser 90 was originally called out as Riser 18B. Figure 4.1 provides a graphic of the location of this riser.

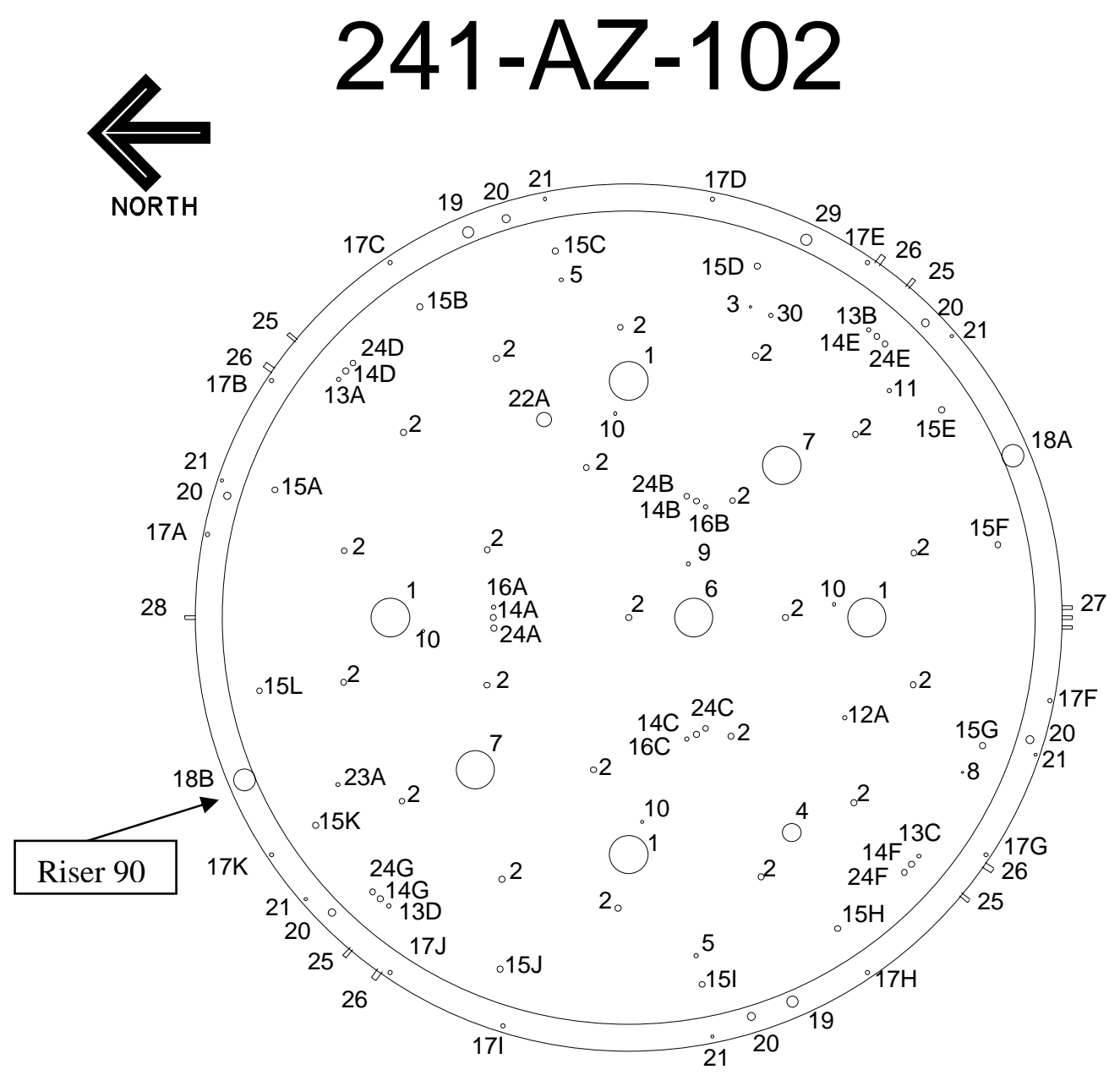

\section{TANK RISER LOCATION}

Ref: Salazar 1994

H-2-67315, Rev.1 H-2-70202, Rev.1

Figure 4.1. UT of 241-AZ-102 from Riser 90 
Figure 4.2 describes the areas on the primary wall of Tank 241-AZ-102 that were ultrasonically examined. Two 15-in.-wide vertical scan paths were performed on Plates \#1, \#2, \#3, \#4, and \#5 below the entrance to Riser 90. A short third vertical scan was performed just west of Vertical Scan \#2. Vertical weld HAZ examinations were done on Plates \#1, \#2, \#3, \#4, and \#5, and the horizontal weld HAZ examination was done on the transition Plate \#5 to knuckle weld. Approximately 270 circumferential inches of the knuckle region was also scanned.

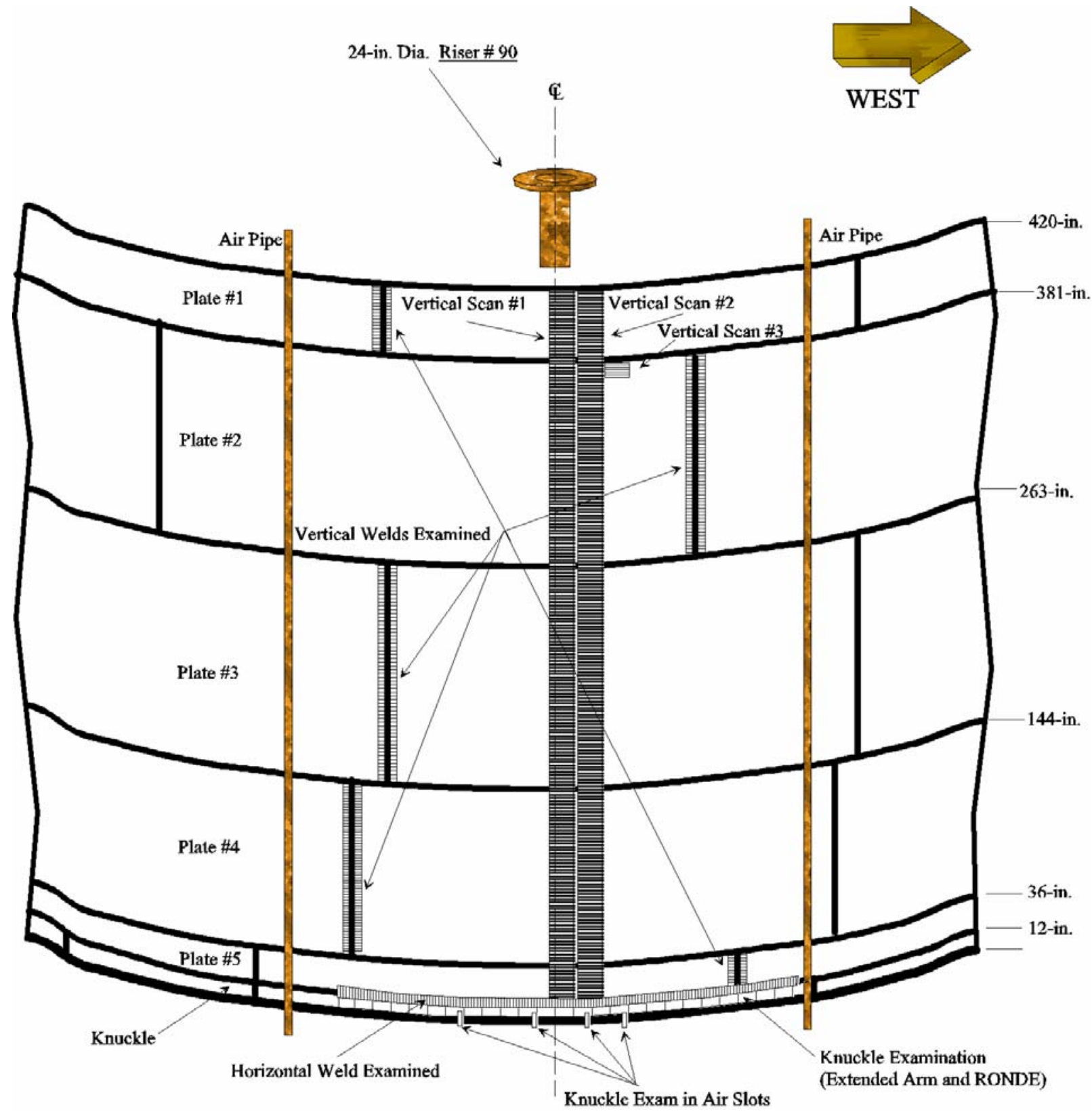

Figure 4.2. Sketch of Scan Paths on Tank 241-AZ-102 


\subsection{Ultrasonic Examination Results}

COGEMA has provided detailed reports including T-Scan and P-Scan hard copies of all areas that were ultrasonically examined to PNNL for third-party review. The data was analyzed by COGEMA Level III Mr. Wes Nelson and peer reviewed by JBNDT Level III Mr. Jim Elder. The results of the examination of Tank 241-AZ-102 are presented in Figures 5.1, 5.2, and 5.3.

Figures 5.1 and 5.2 show the wall thickness examination results for the primary tank wall and the HAZs of both vertical and horizontal welds. The examination consisted of two vertical paths beneath the 24-in. diameter riser and one short vertical path adjacent to Vertical scan \#2. Vertical scan \#1 was 15-in. wide on Plates \#1, \#2, \#3, \#4, and \#5 and started directly below the centerline of the 24-in. riser. Vertical scan \#2 was adjacent to vertical scan \#1 and was also 15-in. wide on Plates \#1, \#2, \#3, \#4, and \#5. Vertical scan \#3 was adjacent to vertical scan \#2 and was also 15-in. wide but only extends approximately 10 -in. on the top of Plate \#2. The HAZs of vertical welds in Plates \#1, \#2, \#3, \#4, and \#5 were examined and the HAZ in the horizontal weld between Plate \#5 and the knuckle section was also examined. Areas in the figures that show two measurements in the same box are the result of the vertical scan paths overlapping the horizontal HAZ scan paths. Figures 5.1 and 5.2 display the minimum readings taken in each 15-in. wide by 12-in. long area of the scan. In the overlapping areas, both minimum readings from each of vertical and horizontal scan paths are given. Highlighted areas in Plate \#1 and Plate \#2 show minimum wall thickness exceeded the reportable level of $10 \%$ of the nominal thickness. The three areas in Plate \#1 are in the HAZ of the vertical weld. The three areas in Plate \#2 are near the end of the plate in the base metal.

Figure 5.3 shows the examination performed on the knuckle of the primary tank wall. The readings distributed around the circumference of the tank knuckle represent the minimum reading in each 12-in. long by 12 -in. wide portion extending down around the knuckle. The four areas denoted as Slot 4 , Slot 1 , Slot A, and Slot B, represent small areas that were scanned extending down to the lower knuckle weld in the air slots. These scan areas are approximately 1-in. long (increment direction around the circumference of the tank), and 7-in wide (scan direction is down around the knuckle and into the air slot) as shown previously in Section 3 of this report.

COGEMA has provided detailed reports and data of all areas of the knuckle region on Tank 241-AZ102 that were ultrasonically examined utilizing the RONDE system to PNNL for third-party review. The data was analyzed by COGEMA Level III Mr. Wes Nelson. Upon receipt of the data, PNNL staff members Susan Crawford and Al Pardini performed a peer review of the results.

The examination consisted of 24 individual scans, each being 12.5-in. in width (circumferential direction). The crawler was moved around the circumference in 10-in. increments, thereby providing for a 2.5-in overlap during data acquisition. The total amount of knuckle scanned was approximately 270-in. measured circumferentially around the tank. The data was displayed in a C-scan (plan) view and provided an image of the entire knuckle, from upper knuckle weld to lower knuckle weld (approximately 19-in. measured on the inside diameter), inclusive of the predicted high-stress region. Further analysis 
was performed on selected data files by PNNL using the SAFT analysis algorithm to verify position of the lower knuckle weld. PNNL was unable to verify that a lower knuckle weld exists on 241-AZ-102.

The results of the examination of Tank 241-AZ-102 indicated no circumferential cracking was present anywhere in the knuckle region between the upper knuckle weld and the predicted lower knuckle weld over the approximately 270 circumferential inches scanned. 


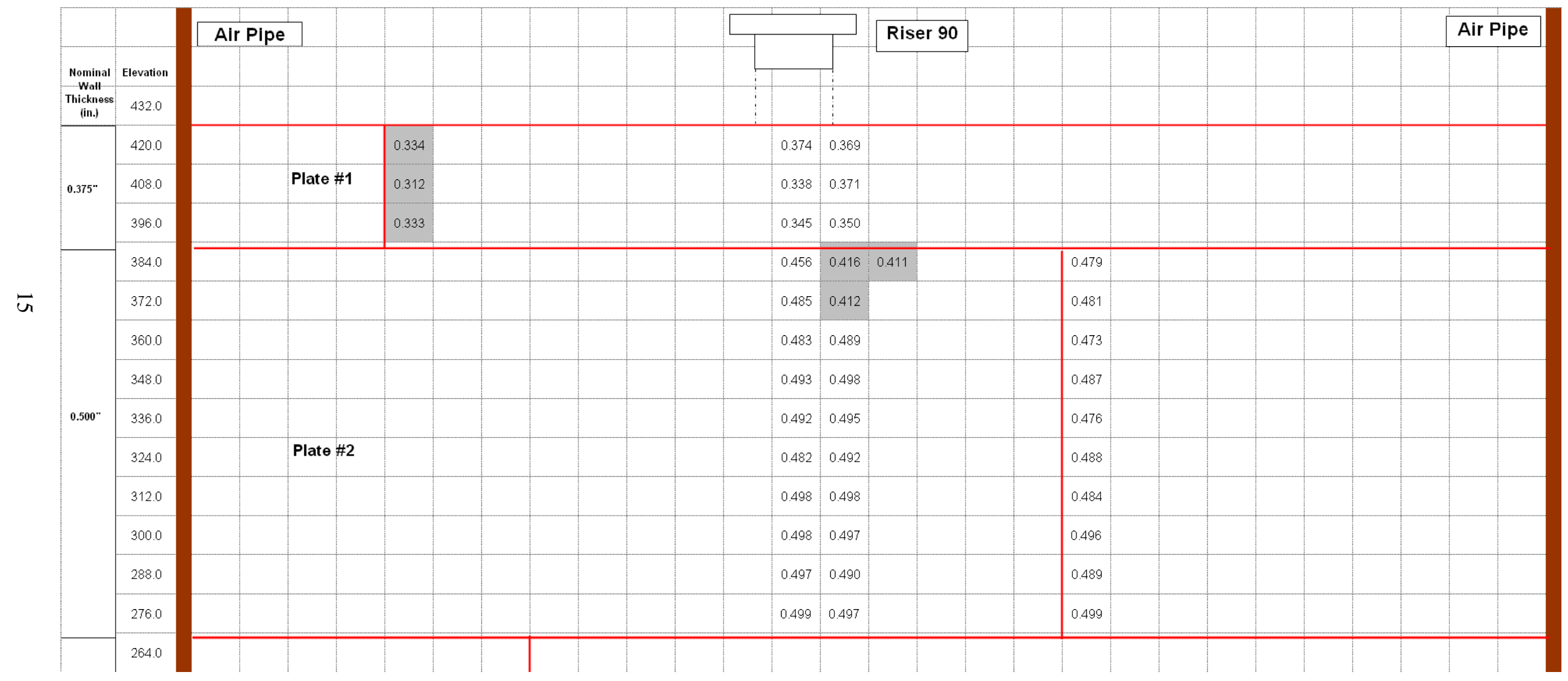

Figure 5.1. UT Data from Tank 241-AZ-102 


\begin{tabular}{|c|c|c|c|c|c|c|c|c|c|c|c|c|c|c|c|c|c|c|c|c|c|c|c|c|c|c|c|}
\hline \multirow{10}{*}{ 0.500" } & 264.0 & & & & & & & 0.482 & & & & & $|0.487|$ & 0.504 & & & & & & & & & & & & & \\
\hline & 252.0 & & & & & & & 0.474 & & & & & 0.494 & 0.506 & & & & & & & & & & & & & \\
\hline & 240.0 & & & & & & & 0.482 & & & & & 0.497 & 0.507 & & & & & & & & & & & & & \\
\hline & 228.0 & Air Pipe & & & & & & 0.479 & & & & & 0.499 & 0.508 & & & & & & & & & & & & & Air $\mathrm{Pi}$ \\
\hline & 216.0 & & & & & & & 0.479 & & & & & 0.499 & 0.511 & & & & & & & & & & & & & \\
\hline & 204.0 & & Plate & & & & & 0.478 & & & & & 0.501 & 0.511 & & & & & & & & & & & & & \\
\hline & 192.0 & & & & & & & 0.487 & & & & & 0.499 & 0.511 & & & & & & & & & & & & & \\
\hline & 180.0 & & & & & & & 0.497 & & & & & 0.501 & 0.511 & & & & & & & & & & & & & \\
\hline & 168.0 & & & & & & & 0.489 & & & & & 0.499 & $\mid 0.508$ & & & & & & & & & & & & & \\
\hline & 156.0 & & & & & & & 0.496 & & & & & 0.499 & \begin{tabular}{|l|} 
\\
\end{tabular} & & & & & & & & & & & & & \\
\hline \multirow{9}{*}{$0.750^{\circ}$} & 144.0 & & & & 0.740 & & & & & & & & 0.759 & $|0.763|$ & & & & & & & & & & & & & \\
\hline & 132.0 & & & & 0.748 & & & & & & & & 0.763 & \begin{tabular}{|l|l|} 
& 0.764 \\
\end{tabular} & & & & & & & & & & & & & \\
\hline & 120.0 & & & & 0.752 & & & & & & & & 0.763 & $|0.763|$ & & & & & & & & & & & & & \\
\hline & 108.0 & & & & 0.748 & & & & & & & & 0.762 & \begin{tabular}{|l|} 
\\
\end{tabular} & & & & & & & & & & & & & \\
\hline & 96.0 & & \multicolumn{2}{|c|}{ Plate \#4 } & 0.749 & & & & & & & & 0.763 & 0.759 & & & & & & & & & & & & & \\
\hline & 84.0 & & & & 0.749 & & & & & & & & 0.763 & \begin{tabular}{|l|} 
\\
\end{tabular} & & & & & & & & & & & & & \\
\hline & 72.0 & & & & 0.752 & & & & & & & & 0.761 & \begin{tabular}{|l|} 
\\
\end{tabular} & & & & & & & & & & & & & \\
\hline & 60.0 & & & & 0.739 & & & & & & & & 0.758 & \begin{tabular}{|l|} 
\\
\end{tabular} & & & & & & & & & & & & & \\
\hline & 48.0 & & & & 0.744 & & & & & & & & 0.752 & \begin{tabular}{|l|} 
\\
\end{tabular} & & & & & & & & & & & & & \\
\hline \multirow{2}{*}{ 0.875" } & 36.0 & \multicolumn{3}{|c|}{ Plate \#5 } & & & & & & & & & 0.880 & $\mid 0.885$ & & & & & & & & & 0.891 & & & & \\
\hline & 24.0 & & 8889 & 088 & 0885 & 0887 & 0881 & 081 & 0884 & 0860 & 088 & 0887 & \begin{tabular}{|l|}
0.878 \\
082
\end{tabular} & \begin{tabular}{|l|}
0.874 \\
0.85
\end{tabular} & 0863 & C849 & 0853 & 0892 & 0868 & 0883 & 0862 & D & \begin{tabular}{|l|}
0.850 \\
0.870
\end{tabular} & 887 & 0888 & 0866 & 0877 \\
\hline $0.875^{\prime \prime}$ & 12.0 & Knukkle & 0.854 & 0.856 & 0.851 & 0.862 & 0.870 & \begin{tabular}{|l|}
0.856 \\
\end{tabular} & 0.865 & 0.864 & $\begin{array}{l}0.867 \\
\end{array}$ & \begin{tabular}{|l|}
0.872 \\
\end{tabular} & \begin{tabular}{|l|}
0.870 \\
\end{tabular} & 0.871 & 0.869 & 0.864 & \begin{tabular}{|l|}
0.856 \\
\end{tabular} & \begin{tabular}{|l|}
0.837 \\
\end{tabular} & \begin{tabular}{|l|} 
\\
\end{tabular} & 0.849 & 0.842 & 0.851 & 0.851 & 0.872 & 0.871 & 0.855 & 0.858 \\
\hline
\end{tabular}

Figure 5.2 UT Data from Tank 241-AZ-102 cont. 


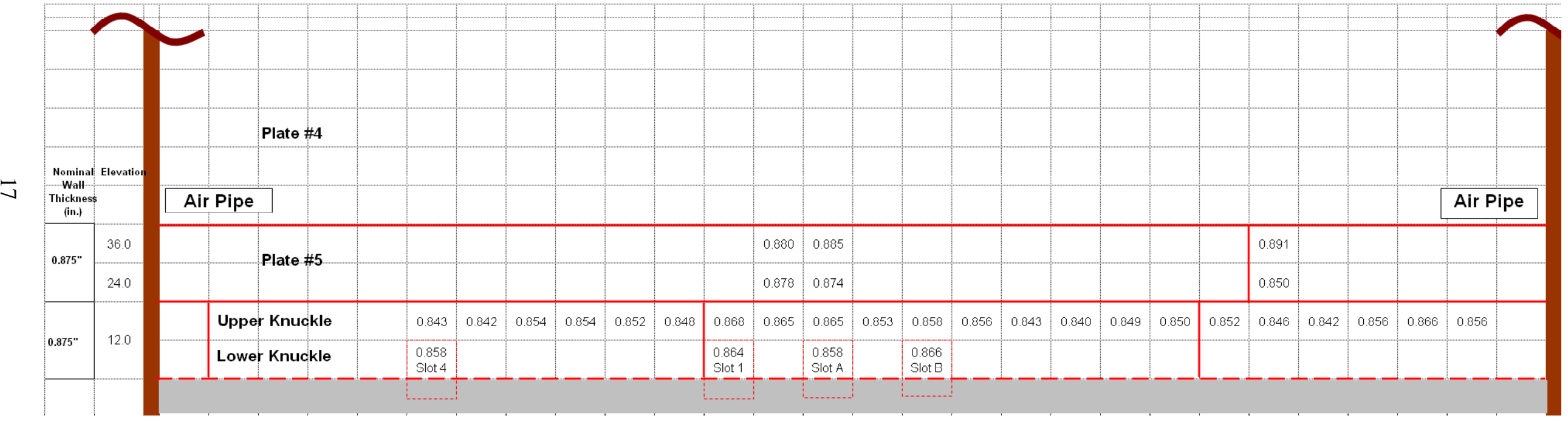

Figure 5.3 UT Data from Tank 241-AZ-102 Knuckle Region 


\subsection{Conclusions}

The results of the examination of Tank 241-AZ-102 have been evaluated by PNNL personnel. The examination consisted of two 15-in. wide scans over the entire height of the tank, one short 15-in. wide scan on the top of Plate \#2, and the HAZs of 5 vertical welds and 1 horizontal weld. Utilizing the Extended-Arm scanner, the examination included the upper portion of the knuckle extending down around the knuckle approximately 12-in. and portions of the lower knuckle extending down to the lower knuckle weld area (high stress region) in 4 areas accessible in the air slot region. The examination was performed to detect any wall thinning, pitting, or cracking in the primary tank wall and knuckle. The knuckle was also examined using the RONDE system for circumferentially oriented cracking.

\subsection{Primary Tank Wall Vertical Scan Paths}

Two 15-in.-wide scan paths were performed on Plates \#1, \#2, \#3, \#4, and \#5 and one short 15-in. wide scan on the top of Plate \#2. The plates were examined for wall thinning, pitting, and cracks oriented vertically on the primary tank wall. The results indicated that the nominal thickness in Plate \#1 is 0.375in. and the minimum thickness in this area was 0.338-in. The minimum thicknesses in the areas scanned with nominal thickness of 0.500 -in. were as follows; Plate \#2 was 0.411 -in. and Plate \#3 was 0.487-in. The nominal thickness in Plate \#4 is 0.750 -in. and the minimum thickness in this area was 0.752 -in. The nominal thickness in Plate \#5 is 0.875-in. and the minimum thickness in this area was 0.874 -in. There were three areas of wall thinning that exceeded the reportable level of $10 \%$ of the nominal thickness. The areas were located near the top of Plate \#2. No pitting or vertical crack-like indications were detected in Plates \#1, \#2, \#3, \#4, or \#5.

\subsection{Primary Tank Wall Weld Scan Paths}

The HAZ of vertical welds in Plates \#1, \#2, \#3, \#4, and \#5 were examined for wall thinning, pitting and cracks oriented either perpendicular or parallel to the weld. The results indicated that the minimum thicknesses in the weld areas scanned were as follows: The nominal thickness of Plate \#1 is 0.375 -in. and the minimum thickness in this weld area was 0.312 -in. The nominal thickness of Plate \#2 is 0.500 -in. and the minimum thickness in this weld area was 0.473-in. The nominal thickness in Plate \#3 is 0.500 -in. and the minimum thickness in this weld area was 0.474-in. The nominal thickness in Plate \#4 is 0.750 -in. and the minimum thickness in this weld area was 0.739-in. The nominal thickness in Plate \#5 is 0.875-in. and the minimum thickness in this weld area was 0.850 -in. There were three areas of wall thinning that exceeded the reportable level of $10 \%$ of the nominal thickness. The areas were located in the HAZ of the vertical weld in Plate \#1. No pitting or crack-like indications were detected in the weld areas in Plates \#1, \#2, \#3, \#4, or \#5.

The HAZ of the horizontal weld between Plate \#5 and the tank knuckle was examined for wall thinning, pitting and cracks oriented either perpendicular or parallel to the weld. The results indicated that the minimum thickness in the weld area with nominal thickness of 0.875 -in. on Plate \#5 was 
0.842-in. The minimum thickness in the weld area with nominal thickness of 0.875 -in. on the knuckle was 0.837 -in. There were no areas of wall thinning that exceeded the reportable level of $10 \%$ of the nominal thickness. No pitting or crack-like indications were detected in the weld areas on Plate \#5 side or on the knuckle side of the horizontal weld.

\subsection{Primary Tank Knuckle Scan Paths}

\subsubsection{Extended-Arm Scanning}

The upper portion of the knuckle area was scanned utilizing the Extended-Arm scanner attached to the AWS-5D crawler. The Extended-Arm scanned the transducers down around the knuckle approximately 12-in. from a starting position 2-in. down from the upper knuckle weld joining Plate \#5 to the knuckle. The knuckle was examined for wall thinning, pitting, and cracks oriented circumferentially around the primary tank. The results indicated that the minimum thickness in the approximately 22 circumferential feet of knuckle area examined with nominal thickness of 0.875 -in. was 0.840 -in. There were no areas that exceeded the reportable level of $10 \%$ of the nominal thickness. No pitting or circumferentially oriented crack-like indications were detected in the upper portion of the knuckle area.

Four small areas on the lower portion of the knuckle area were examined for wall thinning utilizing the Extended-Arm scanner in areas accessible through selected air slots. The four areas examined were in air slots designated as Slot 4, Slot1, Slot A, and Slot B. The results indicated that the minimum thickness in the lower portion of the knuckle area, with nominal thickness of 0.875 -in., in the selected air slots was 0.858 -in. There were no areas that exceeded the reportable level of $10 \%$ of the nominal thickness.

\subsubsection{Remotely Operated Nondestructive Examination Scanning}

The results of the examination of the knuckle region of Tank 241-AZ-102 have been evaluated by PNNL personnel. The UT concentrated on the examination of the knuckle region from the upper knuckle weld to the lower knuckle weld (approximately 19 in. measured on the inside diameter) and extended circumferentially around the tank approximately $270 \mathrm{in}$. The data provided by the COGEMA Level III UT of the results of the examination of Tank 241-AZ-102 indicated no circumferential crack-like indications were present in the approximately 270 circumferential inches scanned of the knuckle region. 


\subsection{References}

Jensen, C. E., 2002, Engineering Task Plan for the Ultrasonic Inspection of Hanford Double-Shell Tanks FY2003, RPP-11832, Rev 0, September 2002, CH2M Hill Hanford Group, Inc., Richland, Washington. 


\section{Distribution}

No. of

Copies

\section{Offsite}

4 DOE/Office of Scientific and

Technical Information \&

Information Release

1 DOE Office of Science and

Technology

Kurt Gerdes

1154 Cloverleaf Building

19901 Germantown Road

Germantown, MD 20874-1290

\section{Onsite}

\section{Hanford Site}
J. L. Castleberry (1)
R3-26
G. P. Duncan (1)
R3-26
C. E. Jensen (2)
R3-26

10 Pacific Northwest National Laboratory

J. W. Brothers (1)

K7-15

L. O. Casazza (1)

K5-26

S. L. Crawford (1)

K5-26

A. F. Pardini (6)

K5-26

G. J. Posakony (1)

K5-26 